\title{
Quest for life satisfaction in the sea of loneliness
}

\author{
Sagaljit Kaur Sekhon ${ }^{1}$, Manjari Srivastava²
}

${ }^{1}$ Guru Nanak Institute of Management Studies, Khalsa College Campus, King Circle, Matunga, Mumbai, India

${ }^{2}$ SVKMs Narsee Monjee Institute of Management Studies, Vile Parle West, Mumbai, India

\begin{abstract}
Background: The aim of this study was to investigate whether workplace loneliness is related to life satisfaction of seafarers on board deep-sea going cargo ships and to determine whether there exist differences in experienced workplace loneliness and life satisfaction between officers and ratings.

Materials and methods: A cross-sectional research design was used to assess the variables in a sample of 521 seafarers sailing on foreign going vessels.

Results: The findings showed that workplace loneliness was an important dimension for determining life satisfaction. As for the differences in the experienced loneliness, the findings show that there is a difference between officers and ratings. The findings support the theory of need for belongingness, which emphasizes the importance of interpersonal relations at work in understanding the well-being among workers.

Conclusions: This study is of practical significance to ship owners and ship managers, where they can use the findings to implement interventions for improving the individual's life satisfaction.
\end{abstract}

(Int Marit Health 2021; 72, 2: 121-128)

\section{Key words: workplace loneliness, life satisfaction, rank, seafarers}

\section{INTRODUCTION}

Life satisfaction is a desirable goal for humans and a happy life has been viewed as a basic human drive [1]. Life satisfaction measures an individual's overall assessment of the life circumstances [2]. Literature has long established the positive correlations with social relationships and support [3], success at the workplace due to its association with better job performance, career satisfaction, organizational commitment, decreased turnover intentions [4] and physical health [5] whereas negative evaluation of life satisfaction is associated with depression and unhappiness [6]. Constructs of happiness, subjective well-being and, life satisfaction are important for society [7]. Reviews of studies on life satisfaction suggest that, it is associated to personality [8] and demographics [9], there is limited focus of research on the work domain [4] especially for emotions like workplace loneliness which has been addressed empirically in a limited way [10].
Essentially, workplace loneliness is a workplace-specific emotion that exists with certain characteristics of the working environment [11]. It is defined as the emotional anxiety caused by the perceived absence of quality workplace interpersonal relationships [12]. Being a negative emotion, the studies have largely explored its dissenting outcomes for organizational identification, commitment and well-being [13], job performance, organizational citizenship behaviour [14], creativity and life satisfaction [15].

The impact of workplace loneliness is attenuated for challenging remote workplaces due to the difficult climatic conditions and limited access to facilities [16]. Working in the shadows, outside of the system and out of mind, seafarers work in conditions characterised by stressful factors like increase in workload due to downsizing, constant call of ports [17], living in limited space, rare shore leaves, volatile climatic conditions, sleep deprivation [18] and frequently changing multi ethic crews [19]. 
Socially a seafarer lives two contradictory lives consisting of his workplace at sea and the other dealing with his personal life related to the families back home. This causes a discrepancy between their personal relationships and their social environment [20] leading to heightened feelings of Ioneliness. The likelihood of such feelings increases due to prolonged absence from home or the loss of a significant other [21]. Additionally, the crew members come from different cultures, rigidly hierarchical ranks and with different linguistic skills. Therefore, seafarers are innately socially dissociated while executing their duties on board [22]. A number of marine accidents have been a result of the social isolation as experienced by the seafarers on board [23]. These conditions affect employees physically and mentally [24]. A study by International Maritime Organization (IMO) revealed the critical role of human error in the accidents on board cargo ships to the extent of $80 \%$ being caused by human factor [25] and that is why this study becomes important as the conditions in which seafarers work may impact them adversely.

Given that human spend as much or more of their lives at work and the critical impact of workplace loneliness on work outcomes, this study aims to investigate the effect of workplace loneliness and recreation support on life satisfaction of sailors who work in an isolated and confined environment.

\section{MATERIALS AND METHODS LITERATURE REVIEW}

The purpose of this section is to provide a comprehensive literature review of life satisfaction and workplace loneliness for suggesting relevant hypothesis, establishing a suitable conceptual framework and identifying appropriate measurements for the study.

\section{LIFE SATISFACTION}

Traditionally, there have been two theoretical approaches to the concept of life satisfaction, i.e., the 'bottom-up' approach and the 'top-down' approach. These approaches differ in terms of the causal assumptions of the factors affecting life satisfaction. The 'top-down' approach asserts that life satisfaction can be explained based on the stable characteristics such as personality [8] and, the "bottom-up' perspective assumes that a person's overall life satisfaction depends on his or her satisfaction in multiple domains in life such as family, finance, friendship, work, leisure, health and the like [26]. Life satisfaction is not an average of the satisfaction experienced in the different life domains owing to the fact that humans have a tendency to weigh the different life domains differently [4]. In effect, both the dispositional and situational factors interact and impact life satisfaction [27]. It would be interesting to in- vestigate life satisfaction as an outcome variable in the domain of management field for enhancing people's lives [4] and therefore the impact of situational variables on life satisfaction is being investigated in the present study. Another important question that needs to be addressed is the identification of the factors that have an ability to influence life satisfaction. Both dispositional variables (e.g., personality) and situational experiences have been shown to predict life satisfaction.

\section{WORKPLACE LONELINESS}

Loneliness is defined as a psychological state that is a result of qualitative or quantitative deficiencies in a person's social relationships [20]. Literature suggests that loneliness can be broadly understood on two distinct dimensions i.e., social loneliness/social companionship and emotional loneliness/emotional deprivation. While social loneliness deals with the absence of satisfactory social relationships or the quantity of the relations; emotional loneliness or deprivation deals with the quality of the employees' relations [28].

The antecedents for loneliness include dispositional factors like personality, shyness, social competence [29], and organisational factors like group coherence, span of control, intense workload, and organizational climate [30]. Research reveals that optimistic feelings correspond to positive outcomes like job performance [31], job satisfaction [32], well-being [3] and life satisfaction [15] whereas negative feelings like loneliness result in mental alterations, abnormal behaviour impacting one's reasoning, and decision-making ability [33] Such undesirable feelings may affect employee commitment, intention to leave [4], employee well-being [11], performance and work alienation [34] to mention a few. These get further compounded for specialised and high-risk occupations like seafaring where inappropriate decisions may lead to situations of life and death.

Furthermore, literature also suggests that loneliness is an occupational hazard for senior-ranked members of an organization [35]. This is often seen as the consequence of maintaining power distance from those lower in the hierarchy of the organization. Since the organization structure is like a pyramid, suggesting the number of employees reduce as the individual moves up the ranks, the scope for meaningful relationships diminishes [36]. Conversely, there are studies that suggest people at the bottom of the organizational hierarchy are more prone to experiencing feelings of loneliness [37]. In the current research, the possibility of difference in the experienced loneliness among the ranks is also explored.

\section{WORKPLACE LONELINESS AND LIFE SATISFACTION}

Experiencing an encouraging workplace environment seemed to correspond positively with life satisfaction, as 
individuals have a ubiquitous need to form enduring and mutually nurturing relationships [38]. Workplace factors including interpersonal relationships among the members significantly promote or spill-over to an individual's wellbeing [39].

Issues related with social relationships in the workplace have been recognised to be key contributors in the stress process and to the outcomes of job and life satisfaction. However, the majority of the studies in the literature have examined the role of social relationships as effects of personal relations like having close friends and being married [40] and a small number of studies have explored the correlation between work-based relationships and life satisfaction. Moreover, this restricted number of studies reveal the possibility that relationships at work may be significant for life satisfaction [41].

The results of this work shall help understand the identifiable gaps in the literature and provide insights into the relationship between dimensions of workplace loneliness, i.e., social loneliness and emotional deprivation, and the identified domains of life satisfaction namely, physical well-being, financial wellbeing, emotional well-being and subjective well-being. Furthermore, presently there has been special attention to the role of personal factors as compared to the environmental factors for studying workplace loneliness [4]. Conventionally it has been observed that measures of Ioneliness correlated negatively with self-reported life satisfaction in elderly research participants [42]. However, similar research has yet to be conducted with different samples belonging to different work groups. Additionally, there are not many empirical studies on workplace loneliness and there is lack of research on the effect of loneliness in the workplace on outcome variables, as most studies have discussed only correlation between the two [43]. The study becomes important due to the sample of seafarers as there have been limited studies on the impact of workplace Ioneliness on life satisfaction in specialised and remote workplaces like seafaring. To further this line of inquiry, it is anticipated that the quality of workplace relationships may commonly influence the individual's feelings about life. Given the admission that work is inherently a fundamental constituent of life, it is reasonable to expect an association between feeling lonely at work and feeling dissatisfied with life [44]. Therefore, the purpose of this paper is to examine the relationship between perceived feelings of loneliness at work that includes the ability to blend into the workplace and "be present, work and function" and life satisfaction. Therefore, it is expected that:

- H1: Workplace loneliness has a significant negative impact on life satisfaction;

- H2: Rank of the seafarer influences their experienced workplace loneliness.

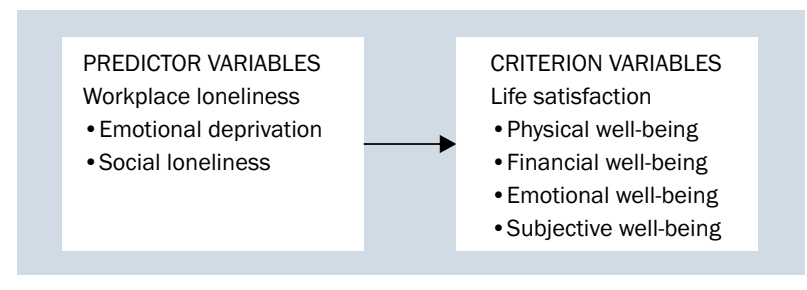

Figure 1. Conceptual model

On the basis of the literature review and the hypothesis formulated, Figure 1 shows the proposed conceptual model for the variables under study.

\section{RESEARCH DESIGN}

\section{Participants}

This research work included Indian seafarers and uses randomisation methods. Instrument was administered via mixed mode i.e., google forms and paper based. The survey was sent to 1077 participants and 588 responses were received, leading to a response rate of $54.11 \%$. The control variables for the study included industry experience of minimum 3 years; sailing experience of minimum 2 years and annual sailing of minimum 6 months in any financial year (April - May). After excluding unfinished responses to the questionnaire, the final research sample included 521 Indian seafarers from different levels of competency; $43.5 \%$ deck officers, 33.6\% engine officers, $23.3 \%$ ratings. Participants had mostly $3-10$ years (61.6\%) of experience. Our sample consisted of $100 \%$ male seafarers and 243 of them were single while 273 of them were married and 5 were divorced. They were working on different types of ship such as tankers (46.4\%), dry bulk carriers (25.9\%), containers (11.9\%) and others (6.2\%). The seniority and the corresponding ratios were as follows: $3-10$ years $-61.6 \%(n=321), 10-15$ years $-15 \%(n=78)$ and above 15 years $-23.4 \%(n=122)$. The total sailing experience was $2-5$ years $-51.4 \%(n=268), 5-10$ years $-23.8 \%(n=124)$ and above 10 years $-24.8 \%(n=129)$.

\section{Instrumentation}

The instruments captured the data by the use of 5-point Likert scales i.e., the loneliness at work scale (LAWS) [27] and the original life satisfaction scale [43]. LAWS has two dimensions i.e., emotional deprivation and social loneliness and life satisfaction scale consists of physical well-being, financial well-being, emotional well-being and subjective well-being, the scales were modified to suit the context of the present study. Appropriateness of data set is analysed in order to identify psychometric qualities of scales for this sample. In this reference, missing values and outliers are defined and multicollinearity, singularity and normality tests 
Table 1. Descriptive statistics for loneliness at work scale (LAWS) and life satisfaction scale

\begin{tabular}{lllllll}
\hline Variables & Items & Scale & Cronbach's $\boldsymbol{\alpha}$ & Skewness & Kurtosis & Common method variance \\
\hline LAWS & 16 & $1-5$ & 0.894 & 0.139 & 0.375 & 30.073 \\
Life satisfaction scale & 18 & $1-5$ & 0.906 & -0.437 & 0.644 &
\end{tabular}

Table 2. Results of exploratory factor analysis

\begin{tabular}{llllll}
\hline Variables & $\begin{array}{l}\text { No. of items } \\
\text { dropped }\end{array}$ & $\begin{array}{l}\text { No. of items } \\
\text { retained }\end{array}$ & $\begin{array}{l}\text { Factors } \\
\text { extracted }\end{array}$ & $\begin{array}{l}\text { Explained } \\
\text { variance (\%) }\end{array}$ & $\begin{array}{l}\text { Cumulative explained } \\
\text { variance (\%) }\end{array}$ \\
\hline Workplace loneliness & 3 & 13 & 1 (ED) & 32.130 & 32.130 \\
& & & $2(\mathrm{SC})$ & 24.901 & 57.031 \\
Life satisfaction & 1 & 17 & 1 (PW) & 25.488 & 25.488 \\
& & & 2 (FW) & 15.217 & 40.705 \\
& & & 3 (EW) & 12.958 & 53.664 \\
\end{tabular}

ED - emotional deprivation; SC - social companionship; PW - physical well-being; FW - financial well-being; EW - emotional well-being; SW - subjective well-being

are conducted. A visual inspection of histograms, normal q-q plots and box plots shows that all scales are approximately normally distributed and Shapiro-Wilk's test $p$ values are more than 0.05 as presented in Table 1. All scales have adequate internal consistency coefficients $(\alpha>0.80)$ and are hence considered reliable. Since the single factor accounts for $30.073 \%$ of variance it is taken as evidence that common method bias is not an issue [44].

\section{STATISTICAL ANALYSIS}

SPSS software 20.0 was used for the evaluation of data and capturing the means and standard deviations (SD) of the variables under study. Correlation and regression analyses were conducted to test the hypotheses for workplace loneliness and life satisfaction. One-way ANOVA was conducted to understand the relation between rank and loneliness. All procedures were performed in compliance with relevant laws and institutional guidelines and that the appropriate institutional committee(s) have approved them. There was no funding received from external agencies for this study. The descriptive statistics are mentioned in Table 1.

\section{RESULTS \\ EXPLORATORY FACTOR ANALYSIS}

Exploratory factor analysis was performed by principal component analysis and all items were found to be higher than $0.40(r>0.30)$, indicating all items took place in the factor analysis. Because some items were below 0.40 or had cross loadings with more than one factor, factor analysis was performed by removing the items one at a time until the ideal solution was achieved. In the workplace loneliness scale three items were dropped. The two factors which evolved were named as emotional deprivation and social loneliness with $\mathrm{KMO}=0.900$ and significance value $(\mathrm{p}=0.00)$.

In the original life satisfaction scale, there were seven domains identified. It was observed that there were high correlations among the satisfaction domains. This indicates that these aspects of life were referring to a similar life functioning area. Hence, factor analysis helped in data reduction and identification of the life domains. This technique helped keep maximum information as it is and avoided the problem of duplication of information. Four main domains of life satisfaction $\mathrm{KMO}=0.890$ and significance value $(p=0.00)$ identified on the basis of the factor analysis are: 1) Physical well-being: Satisfaction with current health; 2) Financial well-being: Satisfaction with the present economic condition; 3) Emotional well-being: Satisfaction with social life, leisure time, family time and work based relations; and 4) Subjective well-being: Global life satisfaction which measures the judgmental component of subjective well-being. This accords flexibility to the subjects to integrate and weigh the life domains as per what they feel is important. The factor loadings of the same have been presented in Table 2.

\section{CORRELATION AND REGRESSION}

Pearson correlation coefficients were computed to determine the significant relationships between dimensions of workplace Ioneliness and life satisfaction (Table 3). All variables under study correlated with each other and as contemplated there was a statistically significant negative correlation between dimensions of workplace loneliness and life satisfaction ( $p<0.001$ for a two-tailed test), based 
Table 3. Intercorrelations of the study variables

\begin{tabular}{lllllllll} 
& Mean & SD & $\mathbf{1}$ & $\mathbf{2}$ & $\mathbf{3}$ & $\mathbf{4}$ & $\mathbf{5}$ & $\mathbf{6}$ \\
\hline 1. WL-ED & 2.08 & 0.716 & 1 & & & & & \\
2. WL-SL & 2.20 & 0.672 & $0.658^{*}$ & 1 & & & & \\
3. LS-PW & 4.13 & 0.662 & $-0.407^{*}$ & $-0.364^{*}$ & 1 & & & \\
4. LS-FW & 3.40 & 0.811 & $-0.294^{*}$ & $-0.371^{*}$ & $0.363^{*}$ & 1 & & \\
5. LS-EW & 3.85 & 0.665 & $-0.463^{*}$ & $-0.518^{*}$ & $0.537^{*}$ & $0.575^{*}$ & 1 & \\
6. LS-SW & 3.45 & 0.720 & $-0.425^{*}$ & $-0.506^{*}$ & $0.522^{*}$ & $0.617^{*}$ & $0.837^{*}$ & 1
\end{tabular}

*Correlations are significant at the 0.01 level (2-tailed); SD - standard deviation; WL - workplace loneliness; ED - emotional deprivation; SL - social loneliness; LS - life satisfaction; PW - physical well-being; FW - financial wellbeing; EW - emotional well-being; SW - subjective well-being

Table 4. Regression analysis results of dimensions of workplace loneliness and dimensions of life satisfaction

\begin{tabular}{|c|c|c|c|c|c|c|c|c|}
\hline \multirow[t]{2}{*}{ Variables } & \multicolumn{8}{|c|}{ Dependent variable - Life satisfaction } \\
\hline & PW & & FW & & EW & & SW & \\
\hline $\begin{array}{l}\text { WL-SL } \\
\text { WL-ED }\end{array}$ & $\begin{array}{l}-0.161^{*} \\
-0.272^{*}\end{array}$ & $\begin{array}{l}F=57.559 \\
R^{2}=0.179 \\
D W=1.886\end{array}$ & $\begin{array}{l}-0.413^{\star} \\
-0.114\end{array}$ & $\begin{array}{l}F=42.886 \\
R^{2}=0.139 \\
D W=1.770\end{array}$ & $\begin{array}{l}-0.442^{*} \\
-0.247^{*}\end{array}$ & $\begin{array}{l}F=108.028 \\
R^{2}=0.292 \\
D W=1.757\end{array}$ & $\begin{array}{l}-0.463^{\star} \\
-0.183^{\star}\end{array}$ & $\begin{array}{l}F=96.240 \\
R^{2}=0.268 \\
D W=1.619\end{array}$ \\
\hline $\begin{array}{l}\text { Workplace } \\
\text { Ioneliness }\end{array}$ & \multicolumn{8}{|c|}{$\beta=-0.547 * ; \mathrm{F}=730.077 ; \mathrm{R}^{2}=0.584 ; \mathrm{DW}=1.714$} \\
\hline
\end{tabular}

Table columns contain standardized $\beta$ coefficients; ${ }^{*} \mathrm{p}<0.01$; DW - Durbin Watson value; WL - workplace loneliness; ED - emotional deprivation; SL - social loneliness; PW - physical well-being; FW - financial wellbeing; EW - emotional well-being; SW - subjective well-being

Table 5. One way ANOVA between rank of the seafarer and workplace loneliness

\begin{tabular}{llllll}
\hline & Sum of squares & Df & Mean square & F & Significance \\
\hline Between groups & 1284.488 & 3 & 428.163 & 5.633 & 0.001 \\
Within groups & 39300.134 & 517 & 76.016 & & \\
Total & 40584.622 & 520 & & &
\end{tabular}

on 521 complete observations ranging from -0.294 to -0.518 . The intercorrelations showed significant negative associations between all indicators of workplace loneliness and life satisfaction. Social loneliness had a strong negative correlation with emotional well-being $(r=-0.518$; $p<0.01)$ and subjective well-being $(r=-0.506 ; p<0.01)$.

Pearson correlation results were significant; therefore, directions of correlation between the variables were investigated with the help of linear regression analysis. Loneliness at the workplace has two dimensions as an independent variable and life satisfaction has three dimensions. For all variables $\mathrm{F}$ and adjusted $\mathrm{R}^{2}$ values are presented in Table 4. Since the Durbin-Watson scores are close to 2 there is no autocorrelation between the variables.

Social loneliness was negatively significant with all indicators of life satisfaction. Physical well-being $(\beta=-0.161$, $p=0.00)$, financial well-being $(\beta=-0.413, p=0.00)$, emotional well-being $(\beta=-0.442, p=0.00)$ and subjective well-being $(\beta=-0.463, \mathrm{p}=0.00)$. Emotional deprivation was found to be significantly predictive of physical well-being $(\beta=-0.272, \mathrm{p}=0.00)$, emotional well-being $(\beta=-0.247$, $p=0.00)$ and subjective well-being $(\beta=-0.183, p=0.00)$. However, emotional deprivation was negative but not significant with financial well-being $(\beta=-0.114, p=0.00)$. The two dimensions of workplace loneliness had combined predictor effects of $54.7 \%$ on life satisfaction ( $F=730.077$; $p<0.01)$. Therefore, the hypothesis $\mathrm{H} 1$ : Workplace loneliness has a significant negative impact on life satisfaction is accepted.

\section{ONE-WAY ANOVA FOR RELATIONSHIP BETWEEN RANK AND LONELINESS}

In order to find the relationship between the rank held by the seafarer and their loneliness, a one-way ANOVA was conducted (Table 5). The participants were divided into four groups based upon their ranks (group 1: deck officer; group 2: deck rating; group 3: engine officer, and group 4: engine rating). An analysis of variance showed that there was a statistically significant impact of rank on loneliness 
at the $p<0.05$ level for all the four conditions $[F(3,517)$ $=5.633, p=0.001]$. Post hoc comparisons using the Tukey HSD test indicated that the mean score for group 1 $(\mathrm{M}=59.81, \mathrm{SD}=9.19,95 \% \mathrm{Cl}=58.56,61.02)$ and group $3(\mathrm{M}=58.44, \mathrm{SD}=8.02,95 \% \mathrm{Cl}=58.44,60.83)$ was significantly different from group $2(\mathrm{M}=56.32$, $\mathrm{SD}=9.04,95 \% \mathrm{Cl}=54.32,58.32)$ and group $4(\mathrm{M}=55.50$, $\mathrm{SD}=8.14,95 \% \mathrm{Cl}=52.89,58.10)$. Therefore, the results suggest that there is a difference in the experienced workplace loneliness amongst the ratings and officers.

There was a statistically significant difference in the experienced workplace loneliness among the officers and ratings. On the basis of the above findings the hypothesis $\mathrm{H} 2$ i.e., the rank of the seafarer influences their experienced workplace loneliness is accepted.

\section{DISCUSSION}

The objective of the present research work was to explore the relationship between experienced workplace loneliness and the life satisfaction of seafarers. In brief, the findings show that workplace loneliness and its indicators i.e., social loneliness and emotional deprivation are important correlates of life satisfaction and its indicators in the maritime industry. As for the rank differences, the findings differ for officers and ratings with respect to perceived workplace Ioneliness. The results of the study are consistent with the previous studies i.e., when feelings of loneliness increase, life satisfaction decreases. The feeling of loneliness, when considered in the organization context, leads to negative emotions and stress which affects the performance levels of the employees adversely. In this study which examined the effects of workplace loneliness on life satisfaction of sailors, the impact is further compounded due to the nature of the profession which is very different from the conventional workplaces. This aspect of the research tries to address the literature gap where the available literature has emphasized the importance of individual factors rather than organizational factors in the evaluation of life satisfaction which is the basis the ongoing dispute of the bottom-up and top-down approach of life satisfaction.

Among the dimensions of life satisfaction, financial well-being was negatively correlated with workplace loneliness dimensions and was not significant with emotional deprivation. This may be explained by the fact that the shipping sector pays the seafarers decently and if a person was working onshore with the same qualifications and technical expertise, he wouldn't have the same earning capacity in the present context for the study. Earning power is one of the major factors which draw seafarers to the shipping sector in addition to the opportunity to explore new places. This finds support in the compensation effect of life satisfaction where dissatisfaction in one domain is compensated for satisfy- ing experiences in other domains [45]. Physical well-being indicator of life satisfaction also correlated weakly with workplace loneliness indicating that the regular mandatory pre-joining medicals for seafarers were helping in keeping a check on the seafarer health resulting in fewer medical conditions. Emotional well-being and subjective well-being had a moderate relation with workplace loneliness as humans as social animals have the need to be accepted by peers and family members. Lack of these meaningful relations leads to a host of emotional issues and affects the individuals' organizational performance [3].

Interestingly it was found that the feelings of loneliness were more pronounced for the officers as compared to the ratings. The officers found it easier to connect when they were sailing at lower ranks; however, as they moved up the ranks, they felt the need to maintain distance from the crew in order to get the work done as they felt it would be easier to get the work done if the rank differentials were prominent. This was also supported by literature as many studies highlight that power creates social distance [46]. However, there are contrasting studies that state that rank can be negatively related to loneliness. As such, during the contractual period, the seafarers' social interactions are limited to a small circle of colleagues and the socialization process includes the formation of temporary bonds among seafarers that are interrupted when they sign-off and new bonds are formed with new on joiners, as is the culture of the seafaring profession [47].

The strength of this study includes a relatively large sample with an acceptable response rate by using recognised and validated instruments. Therefore, the inferences may be generalisable to the larger population, inclusive of research on the workplace environment and employee well-being and satisfaction in general. However, some caution needs to be exercised when interpreting the results from this study as: firstly, the data is based on self-reports and though the data was checked for common-method variance, the results still need to be generalised with caution. Secondly, one cannot draw conclusions about causal relationships as the data was cross-sectional and may be a longitudinal study is needed to attain more knowledge about the causality of the relationships existing between the variables. Furthermore, loneliness being a perception-based variable, it reflects the perceptions of the participants and they may be reluctant to express their emotions; therefore, results may not reflect objectivity.

There is a great deal of complexity created by the needs of the sailors, their families, the shore teams, the charterers, and the organizations. Sailors when they join ships suddenly find themselves in "relational deficit," if not social isolation, at a time when they need more than the usual support. Generally, organizations consider emotional or social issues 
like loneliness as personal problems and not as having an impact on organizational operations. Conversely, studies about loneliness have supported direct effects of the same on outputs such as performance, motivation, etc. [3]. The importance of having positive social relations was also highlighted by Elton Mayo in his Hawthorne studies which laid the ground for the real source of employee motivation and team building [48]. Lonely people often expected less from their jobs and future careers [49]. Although the term Ioneliness is used very casually in daily life, the outcomes of Ioneliness can be far more reaching as seen in the literature review. Therefore, on the basis of the above findings it can be suggested that the organizations can be proactive in order to offset the loneliness feelings and help reduce the consequences of experienced loneliness. The reality necessitates that the top four ranks i.e., captain, chief officer, chief engineer, and second engineer help induce positive social relationships on board. Social activities like get-togethers, indoor game tournaments, and pieces of training related to interpersonal relations covering topics like conflict management, improving social abilities, etc. may be organized for improving social interactions among employees.

\section{CONCLUSIONS}

In conclusion, there are many demanding aspects of seafaring such as the inability of employees to leave the worksite, living in confined workplaces, working with multi-national crews with limited means of communication, extreme weather conditions, long periods away from home, and motion of the workplace. Some of these features can be controlled, modified and adjusted for yet others are a reflection of the nature of the industry. Hence, identification of the important work domain factors may help as a basis for introducing strategies and interventions which can help minimise the negative impact of these factors on the life satisfaction of a seafarer [50]. In the present study, it was evident that interpersonal relations on board are primarily very important in setting off the feelings of loneliness. Hence the findings support the theory of belongingness which focuses on the interpersonal relations among the members of the organization. The rank at which the seafarer sails also is crucial in understanding the loneliness the employee may experience.

Furthermore, while it is important to study loneliness in vulnerable groups, in this paper the group being sailors, it is equally important to examine loneliness across a wider range of the population to allow for valid conclusions and interventions. Another challenge for future studies may be to bring in the aspect of cultural differences to understand the relationship between workplace loneliness and life satisfaction. This study, in the future, maybe extended to include women seafarers where we anticipate that the results may help provide rich insights paving the path for gender comparative studies as currently, their numbers are small as compared to their male counterparts.

\section{REFERENCES}

1. Ho M, Cheung F, Cheung S. Personality and life events as predictors of adolescents' life satisfaction: do life events mediate the link between personality and life satisfaction? Soc Indic Res. 2008; 89(3): 457-471, doi: 10.1007/s11205-008-9243-6.

2. Starr T, Currie G. 'Out of sight but still in the picture': short-term international assignments and the influential role of family. Int J Hum Resour Manag. 2009; 20(6): 1421-1438, doi: 10.1080/09585190902909921.

3. Wright SL. Loneliness in the Workplace. Doctor of Philosophy in Psychology University of Canterbury, Canterbury 2006.

4. Erdogan B, Bauer T, Truxillo D, et al. Mansfield, LR. Whistle while you work: A review of the life satisfaction literature. J Manag. 2012; 38(4): 1038-1083, doi: 10.1177/0149206311429379.

5. Siahpush M, Spittal M, Singh GK. Happiness and life satisfaction prospectively predict self-rated health, physical health, and the presence of limiting, long-term health conditions. Am J Health Promot. 2008; 23(1): 18-26, doi: 10.4278/ajhp.061023137, indexed in Pubmed: 18785370.

6. Proctor C, Linley P, Maltby J. Youth life satisfaction: a review of the literature. J Happiness Stud. 2008; 10(5): 583-630, doi: 10.1007/ s10902-008-9110-9.

7. Blanchflower D, Oswald A. International Happiness: A New View on the Measure of Performance. Acad Manag Perspect. 2011; 25(1): 6-22, doi: 10.5465/amp.2011.59198445.

8. Diener E, Oishi S, Lucas RE. Personality, culture, and subjective well-being: emotional and cognitive evaluations of life. Annu Rev Psychol. 2003; 54: 403-425, doi: 10.1146/annurev. psych.54.101601.145056, indexed in Pubmed: 12172000.

9. Diener Ed, Suh E, Lucas R, et al. Subjective well-being: Three decades of progress. Psychol Bull. 1999; 125(2): 276-302, doi: 10.1037/0033-2909.125.2.276.

10. Firoz M, Chaudhary R, Khan A. Desolated milieu: exploring the trajectory of workplace loneliness (2006-2019). Manag Res Rev. 2020; 44(5): 757-780, doi: 10.1108/mrr-01-2020-0051.

11. Erdil 0 , Ertosun 00 . The relationship between social climate and Ioneliness in the workplace and effects on employee well-being. Procedia Soc Behav Sci. 2011; 24: 505-525, doi: 10.1016/j. sbspro.2011.09.091.

12. Ayazlar G, Güzel B. The effect of loneliness in the workplace on organizational commitment. Procedia Soc Behav Sci. 2014; 131: 319-325, doi: 10.1016/j.sbspro.2014.04.124.

13. Lam L, Lau D. Feeling lonely at work: investigating the consequences of unsatisfactory workplace relationships. Int J Hum Resour Manag. 2012; 23(20): 4265-4282, doi: 10.1080/09585192.2012.665070.

14. Tabancali $E$. The relationship between teachers' job satisfaction and Ioneliness at the workplace. Eurasian J Edu Res. 2016; 16(66): 1-30, doi: 10.14689/ejer.2016.66.15.

15. Dick F, Ponsonby W. Occupational Remote Environments Health. In Remote Medicine: A Textbook For Trainee And Established Remote Healthcare Practitioners. World Scientific Publishing Company, $2020: 237-257$.

16. Smith A, Lane T, Bloor M, Allen P. Fatigue offshore: Phase 2 The short sea and coastal shipping industry. Cardiff: Seafarers International Research Centre (SIRC)/Centre for Occupational and Health Psychology. Cardiff University 2003. 
17. Smith AP, Lane T, Bloor M. Fatigue offshore: A comparison of offshore oil support shipping and the offshore oil industry. Seafarers International research Centre/Centre for Occupational and health. Psychology 2001.

18. Håvold JI. Safety-culture in a Norwegian shipping company. J Safety Res. 2005; 36(5): 441-458, doi: 10.1016/j.jsr.2005.08.005, indexed in Pubmed: 16310804.

19. Peplau L, Perlman D. Perspectives on Ioneliness Loneliness: A source book of current theory, research and therapy. John Wiley, New York 1982: Sons.

20. Sawir E, Marginson S, Deumert A, et al. Loneliness and international students: an Australian study. J Stud Int Educ. 2007; 12(2): 148-180, doi: 10.1177/1028315307299699.

21. Gökçek V, Tavacıoğlu L. A quantitative analysis on leisure participation of Turkish seafarers by structural equation modeling. Engineering Sciences. E-Journal of New World Sciences Academy. 2018; 13(2): 137-155, doi: 10.12739/nwsa.2018.13.2.1a0408.

22. Sampson $\mathrm{H}$, Thomas $M$. The social isolation of seafarers: causes, effects, and remedies. Int Marit Health. 2003; 54(1-4): 58-67, indexed in Pubmed: 14974778.

23. Jaremin B. Work-site casualties and environmental risk assessment on Polish vessels in the years 1960-1999. Int Marit Health. 2005; 56(1-4): 17-27, indexed in Pubmed: 16532582.

24. International Maritime Organization. Guidelines on Fatigue. IMO Publishing 2002.

25. Veenhoven R. Developments in satisfaction-research. Soc Indic Res. 1996; 37(1): 1-46, doi: 10.1007/bf00300268.

26. Heller D, Watson D, Hies R. The role of person versus situation in life satisfaction: a critical examination. Psychol Bull. 2004; 130(4): 574-600, doi: 10.1037/0033-2909.130.4.574, indexed in Pubmed: 15250814.

27. Wright SL, Burt CD, Strongman KT. Loneliness at the workplace: Construct Definition and Scale Development. NZ J Psychol. 2006; 35: 59-68.

28. Wittenberg M, Reis H. Loneliness, social skills, and social perception. Pers Soc Psychol Bull. 2016; 12(1): 121-130, doi: 10.1177/0146167286121012.

29. Ashkanasy N, Nicholson G. Climate of fear in organisational settings: construct definition, measurement and a test of theory. Aust J Psychol. 2006; 55(1): 24-29, doi: 10.1080/00049530412331312834.

30. Raabe B, Beehr T. Formal mentoring versus supervisor and coworker relationships: differences in perceptions and impact. J Organizational Behavior. 2003; 24(3): 271-293, doi: 10.1002/job.193.

31. Herrbach O, Mignonac K, Gatignon AL. Exploring the role of perceived external prestige in managers' turnover intentions. Int J Hum Resour Manag. 2004; 15(8): 1390-1407, doi: 10.1080/0958519042000257995.

32. Hafez AA. Seafarers' social life and its effect on maritime safety with respect to Egyptian seafarer. 46; 1999.

33. Santas G, Isik O, Demir A. The effect of loneliness at work; work stress on work alienation and work alienation on employees' performance in Turkish health care institution. South Asian J Manag Sci. 2016; 10: 30-38.
34. Wright S. Is it lonely at the top? An empirical study of managers' and nonmanagers' loneliness in organizations. The Journal of Loneliness. J Psychol. 2012; 146(1-2): 47-60, doi: 10.1080/00223980.2011.585187, indexed in Pubmed: 22303612.

35. Bell R, Roloff M, Van Camp K, et al. Is It Lonely at the Top?: Career Success and Personal Relationships. J Comm. 2006; 40(1): 9-23, doi: 10.1111/j.1460-2466.1990.tb02247.x.

36. Lucas R, Dyrenforth P, Diener Ed. Four myths about subjective well-being. Soc Personal Psychol Compass. 2008; 2(5): 2001-2015, doi: 10.1111/j.1751-9004.2008.00140.x.

37. Hart P. Predicting employee life satisfaction: A coherent model of personality, work, and nonwork experiences, and domain satisfactions. J Appl Psychol. 1999; 84(4): 564-584, doi: 10.1037/00219010.84.4.564.

38. Myers DG, Diener E. Who is happy? Psychol Sci. 1995; 16: 10-19.

39. Bowling N, Eschleman K, Wang Q. A meta-analytic examination of the relationship between job satisfaction and subjective well-being. J Occup Organ Psychol. 2011; 83(4): 915-934, doi: 10.1348/096317909x478557.

40. Doyle D, Forehand MJ. Life satisfaction and old age. A reexamination. Res Aging. 1984; 6(3): 432-448, doi: 10.1177/0164027584006003008, indexed in Pubmed: 6544992.

41. Zhou X. A review of researches workplace loneliness. J Psychology. 2018; 9(5): 1005-1022, doi: 10.4236/psych.2018.95064.

42. Wright SL. Loneliness in the workplace. University of Canterbury. J Psychol. 2005.

43. Loewe N, Bagherzadeh M, Araya-Castillo L, et al. Life domain satisfactions as predictors of overall life satisfaction among workers: evidence from Chile. Soc Indic Res. 2014; 118: 71-86, doi: 10.1007/ s11205-013-0408-6, indexed in Pubmed: 25018580.

44. Chang SJ, Witteloostuijn Av, Eden L. From the Editors: Common method variance in international business research. J Int Bus Stud. 2010; 41(2): 178-184, doi: 10.1057/jibs.2009.88.

45. Rojas M. Life satisfaction and satisfaction in domains of life: is it a simple relationship? J Happiness Stud. 2006; 7(4): 467-497, doi: 10.1007/s10902-006-9009-2.

46. Lee F, Tiedens L. Is it lonely at the top?: The independence and interdependence of power holders. Res Organ Behav. 2001; 23: 43-91, doi: 10.1016/s0191-3085(01)23003-2.

47. Österman C, Hult C. Administrative burdens and over-exertion in Swedish short sea shipping. Marit Policy Manag. 2016; 43(5): 569-579, doi: 10.1080/03088839.2016.1154994.

48. Bruce K, Nyland C. Elton mayo and the deification of human relations. Organ Stud. 2011; 32(3): 383-405, doi: 10.1177/0170840610397478.

49. Bogler R, Somech A. Influence of teacher empowerment on teachers' organizational commitment, professional commitment and organizational citizenship behavior in schools. Teach Teach Educ. 2004; 20(3): 277-289, doi: 10.1016/j.tate.2004.02.003.

50. Hetherington C, Flin R, Mearns K. Safety in shipping: the human element. J Safety Res. 2006; 37(4): 401-411, doi: 10.1016/j. jsr.2006.04.007, indexed in Pubmed: 17046789. 